\title{
Armas modernas para a guerra santa: Igreja Católia e meio de comunicação em meados dos $\operatorname{anos} 50$
}

\author{
Daniel Vasconcelos Solon
}

A partir da década de 30 do século passado, o Vaticano lançou diversos documentos abordando a ameaça do rádio, cinema e televisão contra a moral e fé católicas. A Igreja Católica, em seguida, propôs uma nova postura frente aos avanços tecnológicos, defendendo a utilização das "novas armas" midiáticas para propagação da fé e para o enfrentamento político contra ideologias de esquerda. As orientações das encíclicas papais, mensagens e outros documentos chegaram às folhas da imprensa católica no Brasil, evidenciando a preocupação da Igreja quanto ao uso dos meios de comunicação. A partir da análise do jornal católico "O Dominical” de Teresina-PI, e de outros semanários locais, em meados dos anos 50, este artigo trata sobre a mudança de abordagem da Igreja frente ao rádio, cinema e imprensa escrita e ainda do processo de consolidação do rádio na capital do Piauí.

Palavras-chave: Igreja - Comunicação História.

From the 30s of last century, the Vatican released several documents addressing the threat of radio, film and television against the Catholic faith and

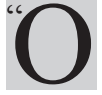

brigado pelo vosso amor e o vosso apoio! Possais viver sempre na alegria que se experimenta quando se põe Cristo no centro da vida", dizia a última mensagem constante no perfil do Papa Bento XVI no microblog Twitter, minutos antes de renunciar ao posto máximo da Igreja Católica Romana, em 28 de Fevereiro de 2013. A decisão de deixar o cargo havia sido anunciada no dia 11 de fevereiro, causando desconfianças diversas e especulações sobre crises e intrigas políticas no centro de poder da Santa Sé.

Quatro dias antes do ato oficial de vacância no Vaticano, Bento XVI postou no Twitter uma mensagem

\footnotetext{
* Mestre em História do Brasil (UFPI) e professor da Universidade Estadual do Piauí (UESPI). dnlsolon@gmail.com
} 
morals. The Catholic Church then proposed a new attitude in the face of technological advances, defending the use of "new weapons" media to spread the faith and the political confrontation against leftist ideologies. The guidelines of papal encyclicals, messages and other documents arrived at the leaves of the Catholic press in Brazil, highlighting the concern of the Church for the use of the media. From the analysis of the Catholic newspaper "O Dominical" from Teresina-PI, and other weeklies in the mid 50s, this paper focuses on the change of the Church approach front media and even the process consolidation of radio in the capital of Piaui.

Keywords: Church - Communication - History

que externava o momento delicado pelo qual passava a Igreja, envolvida em denúncias de escândalos sexuais e transações ilegais no mercado financeiro: "Neste momento particular, peço-vos que rezeis por mim e pela Igreja, confiando sempre na Providência de Deus"'.

Hoje, a utilização da internet e outras tecnologias pela Igreja Católica e por diversas religiões são artefatos de uma verdadeira cruzada midiática, na luta por mais fiéis. As relações entre religião e mídia, no entanto, nem sempre foram harmoniosas. Historicamente, os avanços da ciência e tecnologia, assim como os impactos causados por eles na sociedade, fazem parte das preocupações especialmente da cúpula da Igreja Apostólica Católica, cujo discurso preponderante apontava os meios de comunicação como vilões que ameaçavam a fé e os bons costumes.

Ainda no início da década de 30 do século XX, o Vaticano considerava, em documentos, que o cinema era um poderosíssimo meio de persuasão existente. Era também um pensamento dominante entre governos de outros países, inclusive no Brasil, que vivia o Estado $\mathrm{Novo}^{2}$, cuja relação com a Igreja Católica era das melhores ${ }^{3}$. A Santa Sé via o cinema como um instrumento utilizado para

\footnotetext{
${ }^{1}$ As postagens do Papa Bento XVI, cerca de 40, desde que iniciou a usar o Twitter no final de 2012, foram deletadas das contas oficiais (@pontifex, em inglês, e outras seis línguas) às 16h de 28 de fevereiro de 2013, tão logo configurou-se a vacância do cargo. Os tweets, no entanto, permaneceram disponíveis na agência de notícias do Vaticano na internet. Ver: http://www.news.va/pt/ twitter_archive (último acesso em 28 de fevereiro de 2013).

${ }^{2}$ SIMIS, A. Estado e cinema no Brasil. São Paulo: Annablume, 1996.

${ }^{3}$ A "revolução" de 1930 havia contado com o apoio da Igreja, que tinha como maior liderança no Brasil o bispo Sebastião Leme. Tal apoio resultou em diversas concessões de Vargas à Igreja, inclusive na Constituição de 1934, que contou com o prefácio "sob a proteção de Deus", reconhecimento do casamento religioso pela lei civil, proibição do divórcio, financiamento do Estado para questões de "interesse coletivo" e ensino religioso em escolas públicas. Cf. ALVES, Márcio
} 
influenciar negativamente a conduta de jovens, que se espelhavam nas grandes estrelas e no modo de vida que era disseminado nas películas.

Naquele momento, a preocupação do Vaticano sobre a utilização dos meios de comunicação de massa - especialmente o cinema - era evidente. Não à-toa, antes de inaugurar, em 1931, a Rádio Vaticano com a primeira radiomensagem de um pontífice ao povo católico na história ${ }^{4}$, o papa Pio XI já produzia textos sobre conteúdos veiculados pelo cinema e pelo rádio e a influência destas mensagens no esfacelamento do matrimônio e da família, no desrespeito à castidade, conforme pronunciamento publicado no dia 31 de dezembro de 1930:

[...] Al ponderar la excelencia del casto matrimonio, Venerables Hermanos, se Nos ofrece mayor motivo de dolor por ver esta divina institución tantas veces despreciada y tan fácilmente vilipendiada, sobre todo en nuestros días.

No es ya de un modo solapado ni en la oscuridad, sino que también en público, depuesto todo sentimiento de pudor, lo mismo de viva voz que por escrito, ya en la escena con representaciones de todo género, ya por medio de novelas, de cuentos amatorios y comedias, del cinematógrafo, de discursos radiados, en fin, por todos los inventos de la ciencia moderna, se conculca y se pone en ridículo la santidad del matrimonio, mientras los divorcios, los adulterios y los vicios más torpes son ensalzados o al menos presentados bajo tales colores que parece se les quiere presentar como libres de toda culpa y de toda infâmia[...]. ${ }^{5}$

O Vaticano, desde a Revolução Russa, de 1917, esforçava-se ainda mais para difundir, por todos os meios possíveis, o discurso anti-socialista, cujo eixo baseava-se na encíclica Rerum novarum, lançada pelo papa Leão XIII, em maio de 1891. Os jornais veiculados pela Igreja em todo o mundo, da chamada Imprensa Católica, seguiam uma orientação editorial a partir do que era defendido pela Santa Sé. O papel da religião, naqueles anos de turbulência econômica, política e social entre as duas grandes guerras, era claramente o de pregar a conciliação de classes, a conciliação entre trabalhadores e burguesia, defender a

Moreira. A Igreja e a política no Brasil. São Paulo, Editora Brasiliense, 1979.

${ }^{4}$ A emissora foi inaugurada em 12 de fevereiro de 1931, dois anos depois do Vaticano ser reconhecido pela Itália como Estado independente. O projeto da emissora e sua montagem foram realizados pelo inventor da radiotransmissão, Guilherme Marconi. A rádio começou a operar com um transmissor de ondas curtas de $25 \mathrm{~kW}$, instalado na colina do Vaticano. Ver: RÁDIO VATICANO. In: http://www.aminharadio.com/radio_rvaticano.html (último acesso em 18 de abril de 2005).

${ }^{5}$ Carta CASTI CONNUBII (1930), in: http://www.intratext.com/IXT/ESL0326/ (último acesso em 18 de abril de 2005) 
tradição e moral cristãs vigentes, apoiar a manutenção das relações de produção capitalista e, juntamente com isso, combater o ideário socialista. Pouco depois do início da grande crise econômica mundial de 1929, ao lançar a encíclica Quadragesimo Anno, em 1931, em comemoração aos 40 anos da Rerum novarum, o papa Pio IX reiterou a disposição da Igreja em combater os princípios do socialismo e defender a propriedade privada e o sistema de exploração capitalista, mesmo fazendo leves críticas aos "excessos" do sistema capitalista e necessidade de reformas sociais.

$\mathrm{Na}$ mensagem inaugural da Rádio Vaticano, por exemplo, o papa Pio XI dirigiu-se aos "infiéis e dissidentes" chamando-os para a conversão, além de chamar operários e patrões para manutenção da ordem, "evitando qualquer competição hostil e conflitos mútuos, combinado com aliança fraterna e amigável"'.

No campo político e ideológico, a Igreja externava aos quatro cantos do mundo que dentre os maiores perigos e ameaças à sociedade vinha do marxismo. $\mathrm{O}$ inimigo número um dos católicos foi evidenciado no discurso do papa Pio XI na abertura da Exposição Mundial da Imprensa Católica, em maio de 1936, que reuniu jornalistas católicos de quarenta e cinco nações da Europa e América, e de cinqüenta e três regiões da Ásia, África e Oceania:

O primeiro e maior e mais geral é, certamente, o perigo do comunismo, em todas as suas formas e gradações. Tudo isso ameaça e desafia abertamente ou dissimuladamente mina: a dignidade individual, a santidade da família, da ordem e segurança na sociedade. ${ }^{?}$

Já em 1936, às vésperas da Segunda Guerra, o Vaticano elabora com mais profundidade um documento, a encíclica Vigilanti $\mathrm{Cura}^{8}$, que tratava especificamente sobre o cinema. Logo em sua introdução, o papa Pio XI tece elogios à "Legião da Decência", um movimento deflagrado pelos bis-

${ }^{6}$ IL PRIMO radiomessaggio di Papa Pio XI a tutte te genti e ad ogni creatura. 12 febbraio 1931. Ver em: http://www.vatican.va/holy_father/pius_xi/speeches/documents/hf_p-xi_spe_19310212_ radiomessage_it.html. (Tradução minha.) Último acesso em 10 de novembro de 2010.

${ }^{7}$ ALLOCUZIONE di Sua Santità Pio Xi In Occasione Dell'inaugurazione Dell'esposizione Mondiale Della Stampa Cattolica. 12 maggio 1936. Disponível em http:/www.vatican.va/holy_father/ pius_xi/speeches/documents/hf_p-xi_spe_19360512_siamo-ancora_it.html (tradução minha).

${ }^{8}$ VIGILANTI CURA (1936). Ver em http://www.vatican.va/holy_father/pius_xi/encyclicals/documents/hf_p-xi_enc_29061936_vigilanti-cura_po.html 
pos dos Estados Unidos contra o que consideravam "maus filmes". Nesta encíclica, no entanto, a Igreja já mostra um real interesse em interferir no processo de produção dos filmes, bem como estimular uma fiscalização das obras colocadas em cartaz, catalogando-as entre as que poderiam ou não ser vistas pelos católicos.

No decorrer do documento Vigilanti Cura, Pio XI descreve o poder do cinema e teoriza sobre os motivos pelos quais as películas, sobretudo as faladas, exerciam tanto fascínio sobre as pessoas, fossem elas alfabetizadas ou não.

[...]Não há hoje um meio mais poderoso para exercer influência sobre as massas, quer devido às figuras projetadas nas telas, quer pelo preço do espetáculo cinematográfico, ao alcance do povo comum, e pelas circunstâncias que o acompanham. [...]

[...] O poder do cinema provém de que ele fala por meio da imagem, que a inteligência recebe com alegria e sem esforço, mesmo se tratando de uma alma rude e primitiva, desprovida de capacidade ou ao menos do desejo de fazer esforço para a abstração e a dedução que acompanha o raciocínio. Para a leitura e audição, sempre se requer atenção e um esforço mental que, no espetáculo cinematográfico, é substituído pelo prazer continuado, resultante da sucessão de figuras concretas. No cinema falado, este poder atua ainda com maior força, porque a interpretação dos fatos se torna muito fácil e a música ajunta um novo encanto à ação dramática. Se nos entre-atos se acrescentam danças e variedades, as paixões recebem excitações das mais perigosas, que avultam vertiginosamente. $[\ldots]^{9}$

O documento fala ainda sobre o artifício da beleza e talento de atores e atrizes envolvidos em tramas e romances, onde as músicas de fundo completam a cena, aumentando ainda mais o poder de sedução do cinema, especialmente sobre crianças e jovens:

As variadíssimas cenas no cinema são representadas por homens e mulheres escolhidos sob o critério da arte e de um conjunto de qualidades naturais, e que se exibem num aparato tão deslumbrante a se tornarem às vezes uma causa de sedução, principalmente para a mocidade. O cinema ainda tem a seu serviço a música, as salas luxuosas, o realismo vigoroso, todas as formas do capricho na extravagância. E por isso seu encanto se exerce com um atrativo particular sobre as crianças e os adolescentes. Justamente na idade, na qual o senso moral está em formação, quando se desenvolvem as noções e os sentimentos de justi-

\footnotetext{
${ }^{9}$ Idem, ibidem.
} 
ça e de retidão, dos deveres e das obrigações, do ideal da vida, é que o cinema toma uma posição preponderante. ${ }^{10}$

A preocupação especial da Igreja sobre o cinema frente aos demais meios de comunicação parecia evidente até o início dos anos 50, quando no sul do Brasil vivia-se a época de ouro do rádio e foi inaugurada a TV Tupi, a primeira emissora de televisão do país.

De fato, junto com o passeio ao redor da praça Pedro II, ao som dos alto-falantes, uma parcela da juventude de Teresina, capital piauiense, tinha no cinema uma de suas principais diversões na década de 40 e o american way vendido em cada película hollywoodiana parecia atrair a atenção de jovens e moças da época.

Entre os anúncios de jornais sobre filmes em cartaz nos cinemas da cidade da época, era possível encontrar a propaganda de lojas especializadas em produtos de beleza, prometendo verdadeiros milagres estéticos para as consumidoras, como faz crer a nota "De Hollywoody para você...":

Senhorita:

Quer ser bela como as estrelas do cinema?

Então não vacile... Deixe de usar esses cosméticos que não lhe recomendam bem. Aproveite a experiência das artistas da tela.

Os produtos de beleza da "MAX FACTOR", mundialmente famosos, acabam de ser recebidos diretamente de Hollywood, Califórnia, pela campeã das novidades, a Casa Edilberto Martins, à rua Senador Pacheco, $n^{0} 733$, nesta cidade. [... $]^{11}$

A publicidade da loja de cosméticos seguia descrevendo os benefícios de dois produtos: um pó que corrigia imperfeições da pele e a daria "maciez do veludo" e um batom "essencial para atração de uma boca bonita". E o anúncio publicitário arrematou, com a mesma estratégia persuasiva, utilizando as palavras mágicas de um herói das telas, Ali Babá:

[...] Faça, sem demora, uma visita à Casa Edilberto Martins, onde encontrará todos os produtos de MAX FACTOR, o mago da "maquillage" perfeita das estrelas de Hollywoody, que faz desfilar pela tela as mulheres mais encantadoras do mundo.

Seja uma delas!...

\footnotetext{
${ }^{10}$ Idem, Ibidem.
}

${ }^{11}$ Diário do Piauí, ano 5, n.31, 23 jul 46, p.33 
Agora não há mais dificuldades. Vá hoje mesmo à Casa Edilberto Martins e faça seu "make-up" perfeito.

Os produtos "MAX FACTOR" serão o "Abre-te Sésamo de sua felicidade e encanto pessoal! ${ }^{12}$

A grande quantidade de anúncios de jornais da década de 40 sobre os filmes em cartaz, a grande maioria estrangeiros ${ }^{13}$, induz a pensar que a tela grande realmente atraía grande interesse da parcela da população que poderia pagar pelo ingresso no cinema. Isso parecia reforçar a reflexão da Igreja em ver o cinema como meio de comunicação preponderante até ali.

A propaganda sobre filmes em cartaz, é importante dizer, não era veiculada apenas nos jornais. A Rádio Difusora (a primeira emissora teresinense) e os serviços de alto-falantes (conhecidas ainda por amplificadoras) também divulgavam a programação dos cinemas, sendo que um deles tinha até quadro de resenhas de obras cinematográficas, como afirma Said, ex-locutor da Rádio Amplificadora Teresinense e posteriormente um dos maiores nomes da comunicação no Piauí:

[...] $\mathrm{Na}$ arte de fazer propaganda, em fazer com que os outros se divertissem, ficassem alegres, a gente até (fazia) crítica de cinema: "Hoje no Teatro 4 de Setembro vai passar o filme tal. Olha esse filme é bom, é filme cômico, é filme de guerra, é comédia, é melodrama". "Olha hoje no Rex vai passar um filme tal "[...]. ${ }^{14}$

O gosto popular pelo cinema preocupava seriamente os que faziam a Igreja Católica em Teresina, naquele momento. O jornal "O Dominical”, semanário oficial do clero no Piauí, era o instrumento de contrapropaganda das idéias passadas na maioria das películas que passavam pela cidade, o qual combatia também a moda que se disseminava através das atrizes hollywoodianas.

O próprio ambiente do cinema, escuro e, portanto, propício para troca de carícias entre casais, era tido como mundano pelo clero. Da mesma forma, às

\footnotetext{
${ }^{12}$ Idem, ibidem.

${ }^{13}$ Em 1941, surge no Brasil a companhia de cinema Atlântida, que impulsiona a produção cinematográfica local. Muitos filmes eram estrelados por artistas consagrados no rádio, como o média-metragem Astros em Revista, que contava com apresentação musical de Emilinha Borba, Luís Gonzaga, dentre outros. Ver. GONTIJO, Silvana. O livro de ouro da comunicação. Rio de Janeiro, Ediouro, 2004. p. 394.
}

${ }^{14}$ SAID, Carlos. Depoimento cedido a Daniel Solon, em 4 de janeiro de 2005. 
mulheres era repudiada a prática de passear nas ruas e nas praças - justamente os espaços onde funcionavam os serviços de alto-falante - assim como não eram recomendadas as festas noturnas em clubes. Para a igreja, definitivamente, tais lugares eram impróprios para os rapagões católicos encontrarem as futuras esposas, conforme a nota "Jovens que procurais uma noiva...":

Não a procureis nos lugares mundanos, nos cinemas e nos salões de baile.

Não a procureis entre as moças decotadas que se acham sempre nas ruas, como para pôr-se à venda e lograr algum estúpido.

Procurai a vossa esposa entre as jovens laboriosas, virtuosas, retiradas que têm bom senso e, sobretudo, que têm religião, porque a religião é a base da felicidade nesta e na outra vida. ${ }^{15}$

Aparentemente, a nota acima transcrita havia sido dirigida aos moços católicos. No entanto, o texto foi publicado na Página Feminina, uma seção fixa do jornal O Dominical onde eram difundidos valores a serem seguidos pelas moçoilas. Um espaço no qual o papel social da mulher era claramente definido. A intromissão em assuntos tidos como privativos da esfera masculina - dentre eles, a política - era fortemente combatida em O Dominical. A não obediência aos afazeres do lar eram causadores de feiúra moral, como aponta o texto "Quando é mais feia a mulher":

É feia a mulher, quando fala demasiadamente.

Mais feia, quando ri por ostentação.

Muito mais feia, quando na igreja olha para trás para ver o que se passa.

Pior, quando se ocupa de assuntos políticos.

Atroz, quando se ocupa em falar mal dos conhecido (sic).

Horrível, quando não observa na rua circunspeção de vida.

Catástrofe, quando, presunçosa, crê que só ela há de ser preferida em tudo.

Terremoto, quando descuida dos seus deveres domésticos, para cuidar, como um ídolo, de sua beleza sempre efêmera, sem lembrar de que essa vida é passageira e deve ser uma preparação para a eternidade. ${ }^{16}$

A Igreja não se preocupava somente com o que era projetado no cinema. As próprias salas de exibição eram vistas como um ambiente perigoso que possibilitava, às escuras, transgressões da ordem e costumes impostos à época. Outro fator que preocupava o clero era dificuldade de controle sobre o conglomerado

${ }^{15}$ O Dominical, ano XIV, $10 \mathrm{dez} 1950$, n.49, p.3

${ }^{16}$ Idem, ibidem. 
de jovens em cines, cujos prédios mundanos avizinhavam-se com outros monumentos sagrados da cidade.

[...]Estas nossas observações são tanto mais graves por falar uma representação de cinema não a pessoas separadas, e sim a grandes reuniões, e isto em condições de lugar e tempo que podem levar a um entusiasmo depravado, como também a um ardor ótimo; entusiasmo que pode chegar a uma louca e geral concitação, que pela experiência tão bem conhecemos.

[...] As figuras cinematográficas são mostradas a pessoas sentadas em meia-escuridão e cujas faculdades mentais, e mesmo forças espirituais, estão freqüentemente descontroladas. Não é necessário ir longe para encontrar essas salas; estão em geral ao lado das casas, das igrejas e dos grupos escolares, levando assim o cinema ao meio da vida a sua influência suma e suma importância.[... $]^{17}$

Nitidamente influenciados pela Vigilanti Cura, os cronistas de O Dominical atacavam a utilização do espaço do cinema, bem como o escuro de algumas ruas, por aqueles que buscavam fugir do controle visual da Igreja para troca de carinhos mais ousados. Para o clero, os casais que se comportavam como "pombinhos" nas salas de projeções contribuíam para o desprestígio e perda da pureza da mulher.

[...]Estas leviandades de toda hora que aí vemos por ruas e praças, casaisinhos em arrulhos por becos escuros e em estradas alta hora da noite, estas incríveis e despudoradas atitudes dos Pombinhos em cinemas e nas trevas, as liberdades dos pares de namoradinhos por aí afora, isto é amor?! Nunca! É o desprestígio e o desrespeito da mulher, o túmulo da pureza e a mais desastrosa preparação para o matrimônio[...] $]^{18}$

Assim, a Igreja travava uma ferrenha luta contra obras cinematográficas consideradas imorais, alertando os católicos sobre o perigo que representavam certos filmes à família e aos bons costumes. O jornal $\mathrm{O}$ Dominical, no entanto, ia além da crítica às películas que o rebanho não poderia ver. Mais importante do que combater a chamada Sétima Arte, era mais que urgente arrebatá-la para o lado cristão, como sugere a nota intitulada "Se não conquistarmos o cinema, vão será todo o nosso apostolado":

Qualquer que seja o valor de todas as outras atividades apostólicas, quaisquer que sejam os projetos da Ação Católica, se não conquistar o cinema, estéril será nosso apostolado.

\footnotetext{
${ }^{17}$ VIGILANTI CURA, op. cit.

${ }^{18}$ BRANDÃO, Ascânio. É pecado namorar? O Dominical, ano XIV, 19 nov 1950, n.46, p.3
} 
Como campos preferidos da atividade católica, sempre se assinalaram a escola e a imprensa. Hoje se tem acrescentado as obras sociais. Porém a escola, imprensa, e sociologia passaram à retaguarda, ante o cinema que em pouco tempo se adiantou imensamente entre os demais meios de conquista. Quanto se ensine nas escolas, quanto se defenda ou se propague no livro ou no periódico, quanto se organize no campo social, o cinema contrário o esteriliza. ${ }^{19}$

A referida nota diz mais do que a importância do cinema como forma de conquista. Ela acaba mostrando ainda que, até aquele momento, a igreja no Piauí poderia até ver a radiodifusão um importante meio de comunicação e persuasão, mas a supremacia entre os meios de comunicação para formar opinião era do cinema, arma moderna que deveria ser empunhada em defesa dos valores católicos. A vigilância, no entanto, continuava firme contra obras escritas ainda no século XIX, como o romance "Os miseráveis" (1862), que estariam no índice de livros proibidos pela Igreja, cuja leitura seria "pecado mortal" (Figura 01)

A mudança de foco da Igreja com relação aos meios de comunicação se deu nos anos seguintes, sobretudo na segunda metade da década de 50, quando evidenciou-se a necessidade de se investir com mais profundidade no rádio. Isso não quer dizer que, até o início da década em questão, o clero piauiense desprezasse oportunidades para ocupar espaços na única emissora local, competindo assim com marchas de carnaval e músicas de duplo sentido, tão condenadas pela Igreja. O meio radiofônico era visto ao mesmo tempo como algo profano e sagrado, pelo Vaticano.

Segundo Lima:

[...] o rádio só era visto pela igreja como "sagrado" quando levava ao ar programas de cunho católico. Quanto aos programas ditos não católicos, eram vistos como uma ameaça à moral cristã e aos bons costumes da sociedade, sendo considerados como instrumentos que desvirtuam a sociedade por serem pouco educativos e culturais. ${ }^{20}$

${ }^{19}$ O Dominical, ano XIV, 24 set 1950, n.38, p.4

${ }^{20}$ LIMA, Nilsângela Cardoso. ZQY-3: No ar, a primeira rádio teresinense. 2002, p. 60. Trabalho de Conclusão de Curso. (Graduação em Licenciatura Plena Em História) - Universidade Federal do Piauí. 


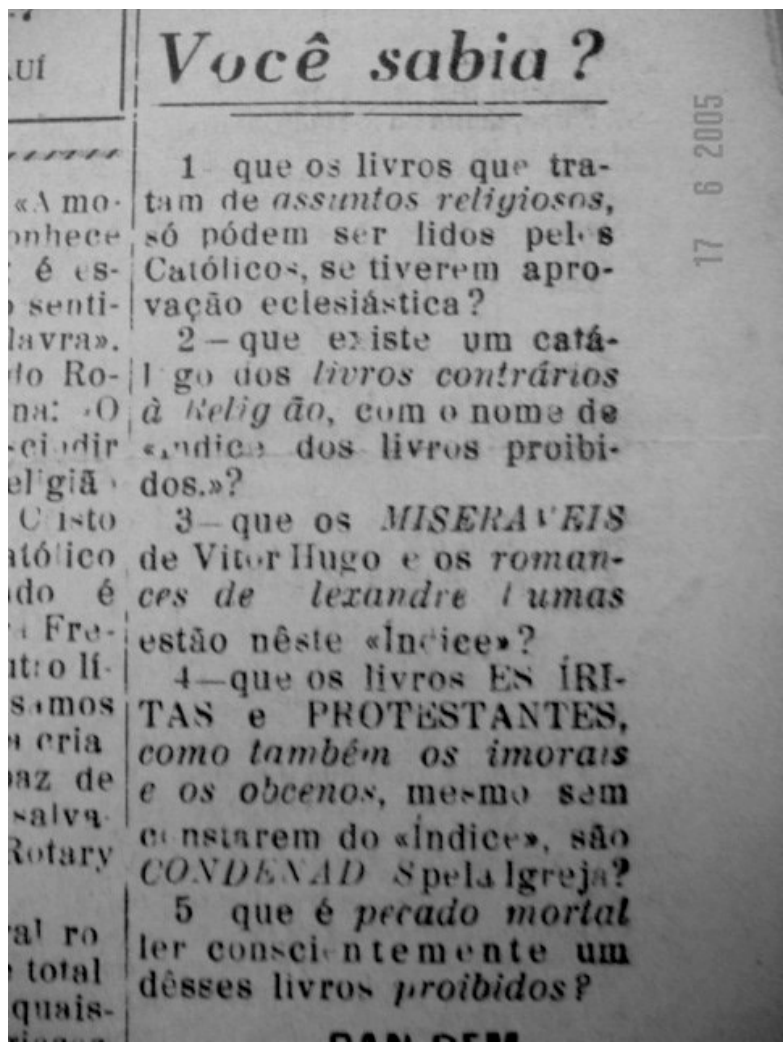

Figura 01: Foto do jornal “O Dominical”: Ano XII, 22 de agosto de 1948.

Já em 1951, a igreja no Piauí lança o "Programa Católico Radiofônico" sob a orientação do arcebispo D. Severino, sendo irradiado às quintas-feiras das $20 \mathrm{~h}$ às $20 \mathrm{~h} 30$ diretamente do estúdio da Rádio Difusora, dando notícias e avisos sobre as atividades destinadas aos católicos, assim como números musicais cristãos. O programa inaugural aconteceu no dia 19 de abril, no Paço Episcopal por D. Severino, e tinha "óbvia a finalidade de levar através de um meio moderno [...] aos lares católicos a doutrina cristã [...] para desapaganizar o que de pagão se verifica infelizmente na sociedade hodierna". ${ }^{21}$

Enquanto o clero no Piauí começava a explorar as ondas da rádio Difusora, inaugurada em 1948, em outros centros urbanos mais desenvolvidos, como São Paulo e Rio de Janeiro, a Igreja já começava a se preocupar também como outra tecnolo- 
gia, a televisão, que no Brasil nasceu como um "subproduto do rádio", ${ }^{22}$ ao empregar inicialmente a mesma linguagem e fazer uso dos mesmos artistas. A preocupação do clero local era com a programação pagã no rádio e também com o avanço do protestantismo, que também utilizava espaço na Difusora. O programa radiofônico dos protestantes era expressamente proibido aos católicos, em O Dominical. ${ }^{23}$

Com o decorrer dos anos, percebendo não só a grande importância do cinema como meio de comunicação, o Vaticano passou a discutir com mais profundidade sobre a necessidade de utilização de rádio e da televisão, assim como a tarefa urgente de tentar controlar o conteúdo de tais mídias.

A igreja estava em guerra, portanto, contra a doutrina marxista, contra o materialismo histórico e a influência da revolução bolchevique de 1917, na Rússia, vista como nação propagadora do ateísmo. A guerra também se dava contra a indústria do cinema e as emissoras de rádio não católicas, que veiculavam produtos considerados nocivos à moral e à fé cristãs, ou que divulgassem outras religiões. E se havia guerra, era necessário usar "armas modernas" para combater o inimigo:

Novos tempos requerem novos homens. Novas lutas, novos equipamentos. Para novas guerras exigem-se novas armas. A época do arco, da flexa e do bodoque já passou! Para inimigos modernos, estratégia moderna! A cavalaria da velha guarda recua. As ligeiras tropas de choque avançam céleres. Assim será na ação católica, que requer táticas e estratagemas modernos. Novos adversários só poderão ser silenciados com baterias modernas que esteja à altura do agressôr. Sus, pois, à ação católica com armas modernas! Uma das mais prestigiosas armas modernas, é, dúvidas não haja, a imprensa católica, arma de precisão e de grande eficiência!...24

Como reflexo dos debates internos da Igreja em âmbito internacional, em outubro de 1956 foi realizada em Teresina a Conferência dos Bispos da Província Eclesiástica do Piauí, já sob o comando do arcebispo Dom Avelar Brandão Vilela. Dentre os temas debatidos no evento, constava a "Formação da opinião pública através dos agentes de publicidade - Imprensa, Cinema, Rádio, Teatro e Televisão". ${ }^{25}$ É curioso destacar que os sinais de televisão no Piauí só chegaram

${ }^{22}$ GONTIJO, Gontijo. Op. cit., p. 415.

${ }^{23}$ O Dominical, Teresina, p.1, 7 set 1952.

${ }^{24}$ BENVINDO, Frei Destêfani. Armas modernas!... O Dominical, Teresina, p.1, 18 jul 1948.

${ }^{25}$ O DIA. Teresina, p.3, 14 out 1956. 
com qualidade a partir da década de 70, mas mesmo assim tal meio de comunicação foi discutido na conferência.

No ano seguinte, o Vaticano lançou a encíclica Miranda Prorsus. No documento, Pio XII dava uma nova orientação para os católicos no que se refere aos principais meios de comunicação na ordem de importância para a Igreja até aquele momento: o cinema, o rádio e a televisão.

A Miranda Prorsus era bem enfática para mostrar o grau de interesse da Igreja em ter nas próprias mãos os meios de comunicação de massa, para propagação de sua doutrina. O Vaticano não achava apenas que tinha o direito de obter concessões na radiodifusão. $\mathrm{O}$ discurso, na verdade, era de que o poder público tinha a obrigação de liberar os canais que fossem necessários para a Igreja Católica, como se ressuscitasse a teoria do direito divino:

A Igreja, depositária da doutrina da salvação e dos meios de santificar, goza do direito inalienável de transmitir as riquezas que lhe foram confiadas por disposição divina. A tal direito corresponde, por parte dos poderes públicos, o dever de lhe tornar possível o emprego das técnicas de difusão. Os fiéis, conhecedores do inestimável dom da Redenção, não se devem poupar a esforços a fim de a Igreja poder servir-se das invenções técnicas e usá-las para a santificação das almas. ${ }^{26}$

A mesma encíclica trouxe ainda o tema de utilização dos meios de comunicação para a educação das massas, que não deveria estar desassociada da doutrina católica, algo que deve ter influenciado profundamente o clero piauiense no projeto de criação da Rádio Pioneira de Teresina, inaugurada em 1962.

O mesmo se pode dizer e com mais razão do ensino, ao qual o filme didáctico, a rádio e mais ainda a televisão escolar, oferecem possibilidades novas e inesperadas, e não só para os jovens mas também para os adultos. Todavia a utilização no ensino destas novas e prometedoras técnicas, não deve opor-se aos imprescritíveis direitos da Igreja e da família no campo da educação da juventude. Em especial ousamos esperar que as técnicas de difusão, - quer estejam nas mãos do Estado, quer se encontrem confiadas à iniciativa particular - não se venham nunca a tornar responsáveis dum ensino sem Deus. ${ }^{27}$

\footnotetext{
${ }^{26}$ MIRANDA Prorsus. Disponível em: http://www.vatican.va/holy_father/pius_xii/encyclicals/ documents/hf_p-xii_enc_08091957_miranda-prorsus_po.html. Último acesso em 23 abril 2006.
}

${ }^{27}$ MIRANDA Prorsus, Op. cit. 
A preocupação com a educação das massas por parte da Igreja e a utilização dos meios de comunicação para tal fim refletiam as mudanças que estavam sendo geradas no interior da Igreja, culminando em ações práticas em prol dos setores mais pobres da sociedade, sobretudo a partir da realização do Concílio Vaticano II, “aberto pelo papa João XXIII em 1962 e encerrado em 1965". ${ }^{28}$

De acordo com José Maria Vieira de Andrade,

Na passagem do final dos anos 50 para os anos 60 do século XX, num contexto de grande efervescência em quase todos os setores sociais, a Igreja Católica passou por processos de mudanças na sua organização em suas bases ideológicas, as quais tinham por fundamento a tentativa da instituição de reaver o seu próprio papel social. ${ }^{29}$

$\mathrm{Na}$ verdade, a Igreja se viu também pressionada a mudar de postura como reação ao crescimento da ideologia socialista, de distribuição de renda e erradicação da pobreza, sobretudo depois do final da Segunda Guerra Mundial. No Brasil, o resultado do pensamento mais alinhado à classe menos favorecida foi a criação do Movimento de Educação de Base (MEB), que teve estreita ligação com a proposta de instalação de escolas radiofônicas através da Rádio Pioneira de Teresina.

[...] Os católicos decidiram investir na criação de vários movimentos direcionados a área educativa e de cultura popular, entre os quais se destacou o MEB, fundado por meio de uma parceria entre a Conferência Nacional dos Bispos do Brasil (CNBB), sua mentora e organizadora, e o Governo Federal, na condição de financiador. ${ }^{30}$

A criação da Rádio Pioneira de Teresina impulsionou o trabalho da Igreja em utilizar os meios de comunicação a favor da evangelização e da propagação dos dogmas católicos no Piauí. A emissora se consolidou no Piauí ao ir além do trabalho religioso, investindo no radiojornalismo, na prestação de serviços e em programas musicais.

\footnotetext{
${ }^{28}$ NASCIMENTO, Francisco Alcides do. História e Memória da Rádio Pioneira de Teresina. Teresina: Alínea Publicações Editora, 2004, p. 47.

${ }^{29}$ ANDRADE, José Maria Vieira de. Pelas ondas da Rádio Pioneira de Teresina: história, sociedade e cultura em sintonia. Monografia (Licenciatura Plena em História), Teresina, UFPI, 2005, p. 45.

${ }^{30}$ Idem, ibidem.
} 


\section{Conclusões}

Ao longo deste artigo, através da análise de documentos do Vaticano (encíclicas, cartas, mensagens), da leitura da imprensa católica (jornal O Dominical), assim como de outros jornais, mostrou-se como a Igreja Católica ajustou discursos e práticas em torno dos meios de comunicação, da década de 30 a 50 do século passado, dentro do contexto da inauguração da primeira emissora de rádio de Teresina. Diante dos avanços das tecnologias, inicialmente vistos como ameaças à fé cristã, a Santa Sé passou não só a lutar pelo controle do que era veiculado nos meios de comunicação, mas também produzir os conteúdos, utilizando a imprensa católica, o rádio e o cinema, este último, sendo considerado, por algum tempo, o mais poderoso veículo de propagação pela Igreja. Os documentos analisados para construção deste artigo conceberam mais elementos para se compreender o processo de utilização e controle dos mais variados meios de comunicação, tais quais os conhecemos hoje, pelas mais variadas religiões no País. 
